\title{
Sensory nerve conduction in the upper limbs at various stages of diabetic neuropathy ${ }^{1}$
}

\author{
P. NOËL
}

From the Brain Research Unit, University of Brussels, Belgium

SUMMARY In 59 diabetic patients, sensory nerve potentials were recorded at various sites along the course of the median nerve. Pathological responses were characterized by reduced amplitude, desynchronization and decreased conduction velocity $(\mathrm{CV})$. Four groups of patients with increasingly severe nerve dysfunction were distinguished. The presence and severity of clinical neuropathy in the upper limbs could be related to decreased maximal sensory nerve $\mathrm{CV}$ in the proximal segment of the limbs. When maximal sensory nerve CV was normal above the wrist, neuropathy usually remained latent. In severe cases where no sensory nerve potentials could be recorded, the cerebral evoked potentials nonetheless permitted a precise evaluation of the somatosensory conduction. In these cases, maximal sensory nerve CV was very low. In five patients with a so-called diabetic mononeuropathy, abnormal nerve potentials were recorded in the median nerve, although no clinical signs could be seen in the corresponding territory. It is proposed that the diabetic nature of a mononeuroe pathy can be assessed by the finding of latent abnormalities in seemingly normal nerve.

Previous electrophysiological studies of diabetic neuropathies have dealt mainly with voluntary electromyography and with the evaluation of motor nerve conduction velocities (CV). These were repeatedly shown to be reduced in patients both with and without clinical evidence of neuropathy (Lawrence and Locke, 1961; Mulder et al., 1961; Gregersen, 1967; Lamontagne and Buchthal, 1970).

Sensory nerve potentials studies have been less frequently reported (Downie and Newell, 1961; Lamontagne and Buchthal, 1970; Noël et al., 1971). They should, however, be particularly rewarding in evaluating a peripheral nerve dysfunction (Gilliatt and Sears, 1958):

1. In sensory nerve potentials, an increase in temporal dispersion may be the earliest sign of impairment when conduction velocity along the fastest fibres is still within the normal range (Gilliatt and Willison, 1962).

2. Sensory nerve fibres are often affected earlier than motor fibres (Gilliatt and Sears, 1958; Buchthal and Rosenfalck, 1971). This is particularly true in diabetes mellitus where

1 This work was supported by a grant from the Fonds de la Recherche Scientifique Medicale to the Brain Research Unit. sensory neuropathy is the most common clinica form of peripheral nerve involvement (Bischof 1963; Pirart, 1965; Eliasson, 1971).

The somatosensory cerebral evoked potentia (CEP) provide additional evidence for abnormal function in the central neurones, but they are also quite useful to assess peripheral nerve function. Apart from important changes in amplitude and waveform (Halliday and Wakefield, 1963; Giblin, 1964; Noël and Desmedt, 1972), the cerebral responses are significantly delayed in patients with lesions of the somatosensory pathway (Desmedt et al., 1966; Desmedt, 1971). Moreover, a valuable estimation of the sensory $\mathrm{CV}$ in the peripheral nerve can be obtained by comparing the latencies of the cerebral potentials evoked by stimulation of the nerve at various sites (Desmedt et al., 1966; Ball et al., 1971; Desmedt et al., 1973). This method is particularly useful in such pathological cases where the sensory nerve potential cannot be recorded (Desmedt and Noël, 1973).

In the present study, sensory nerve and cerebral evoked potentials were used to evaluate the sensory conduction in the distal and proximal median nerve of diabetic patients. The electro- 
physiological findings were compared with the clinical data.

\section{METHODS}

Fifty-nine diabetic patients with and without clinical evidence of neuropathy were investigated. Thirtyeight were male and 21 female. Age ranged from 18 to 68 years. The known duration of diabetes mellitus was a few months to 30 years. The patients were submitted to standard neurological examination with emphasis on sensory modalities in the four limbs. However, no examination methods other than those commonly used in neurological practice were used, so that minor defects such as those involving twopoint discrimination and light touch might not have been detected (Heinrichs and Moorhouse, 1969; Chochinov et al., 1972). Patients presenting clinical evidence of neuropathy in the upper limbs were included if: (1) the signs were not restricted to the median nerve, which could have resulted from a carpal tunnel syndrome; (2) there was no evidence of cervical rib or radiculopathy.

Arterial disease was looked for by oscillometry in the four limbs. None of the patients had any detectable circulatory defect in the upper limbs. Serological examination ruled out syphilis. Alcoholics were excluded.

A group of 55 normal subjects of comparable age and sex distribution was used as control.

The electrophysiological methods that were used have been described in detail (Debecker and Desmedt, 1964; Desmedt, 1971; Desmedt and Noël, 1973). The subjects were lying quietly on a couch in a sound-proofed air-conditioned electrically shielded room $\left(24^{\circ} \mathrm{C}, 50 \%\right.$ humidity $)$. The temperature of the skin over the nerves was maintained at $34^{\circ} \mathrm{C}$, so that the nerve temperature can be assumed to be 35 $37^{\circ} \mathrm{C}$. The stimulus was a square electrical pulse of $0.2 \mathrm{msec}$ delivered to digits II and III through silver ring electrodes with the proximal cathode close to the metacarpophalangeal joint.

Sensory nerve potentials were recorded through fine uninsulated stainless steel needles, the active electrode being inserted close to the median nerve at several sites from the wrist to the supraclavicular notch, and the reference electrode being placed subcutaneously one $\mathrm{cm}$ therefrom at right angles to the nerve.

Somatosensory cerebral evoked potentials were recorded through fine subcutaneous needles, the active electrode being on the parietal focus for the hand in the contralateral hemisphere and the reference on the mid upper forehead.

The responses were fed into an oscilloscope triggered by each stimulation and $64-2,056$ responses were averaged with a digital computer Fabritek I062 with sweeps of 50 or $100 \mu \mathrm{sec} /$ address as necessary to define the potential. The interval between the stimulus artefact and the onset of the initial negative deflection was taken as the latency.

It was also possible to stimulate the median nerve trunk through the same electrodes as were used for recording sensory nerve potentials, thereby evoking larger cerebral responses.

\section{RESULTS}

Standard clinical examination revealed no sign of nerve impairment in 26 patients. In this group the mean age was 43 years (ranging from 25 to 68 years) and the known duration of diabetes ranged from one to 30 years (mean: eight years).

In 17 other patients, mild neurological signs were found in the lower limbs-namely, impaired vibration sensation at the ankle and reduced Achilles tendon reflexes. Feet paraesthesiae and muscular pain of cramping character were occasionally reported and were considered as evidence of a sensory polyneuropathy (Bruyn and Garland, 1971). In 11 other patients, a motor and sensory polyneuropathy involving the lower and upper limbs was found. Amyotrophy and muscle paresis were conspicuous features in six. One patient exhibited a pseudotabetic syndrome with ataxia of gait and painless ulcers of the soles. In these 28 patients with clinical evidence of neuropathy, age ranged from 18 to 68 (mean 53) years and the known duration of diabetes ranged from 1 to 38 (mean 12) years.

In the five remaining patients, the motor involvement affected a mononeuropathic pattern without evidence of traumatic or pressure neuropathy on clinical and radiographic examination. In three, the clinical examination of the lower limbs disclosed unequivocal but mild signs of sensory neuropathy. The ulnar (two patients), peroneal (two patients), or femoral (one patient) nerves were affected.

MAXIMAL SENSORY NERVE CONDUCTION VELOCITY (CV) Sensory nerve potentials could be recorded in nine of the 11 patients presenting a neuropathy involving the lower and upper limbs. The maximal sensory nerve $\mathrm{CV}$ ranged between 18 and $38 \mathrm{~m} / \mathrm{sec}$ in the fingers-to-wrist segment and between 30 and $56 \mathrm{~m} / \mathrm{sec}$ in the wrist-to-arm 


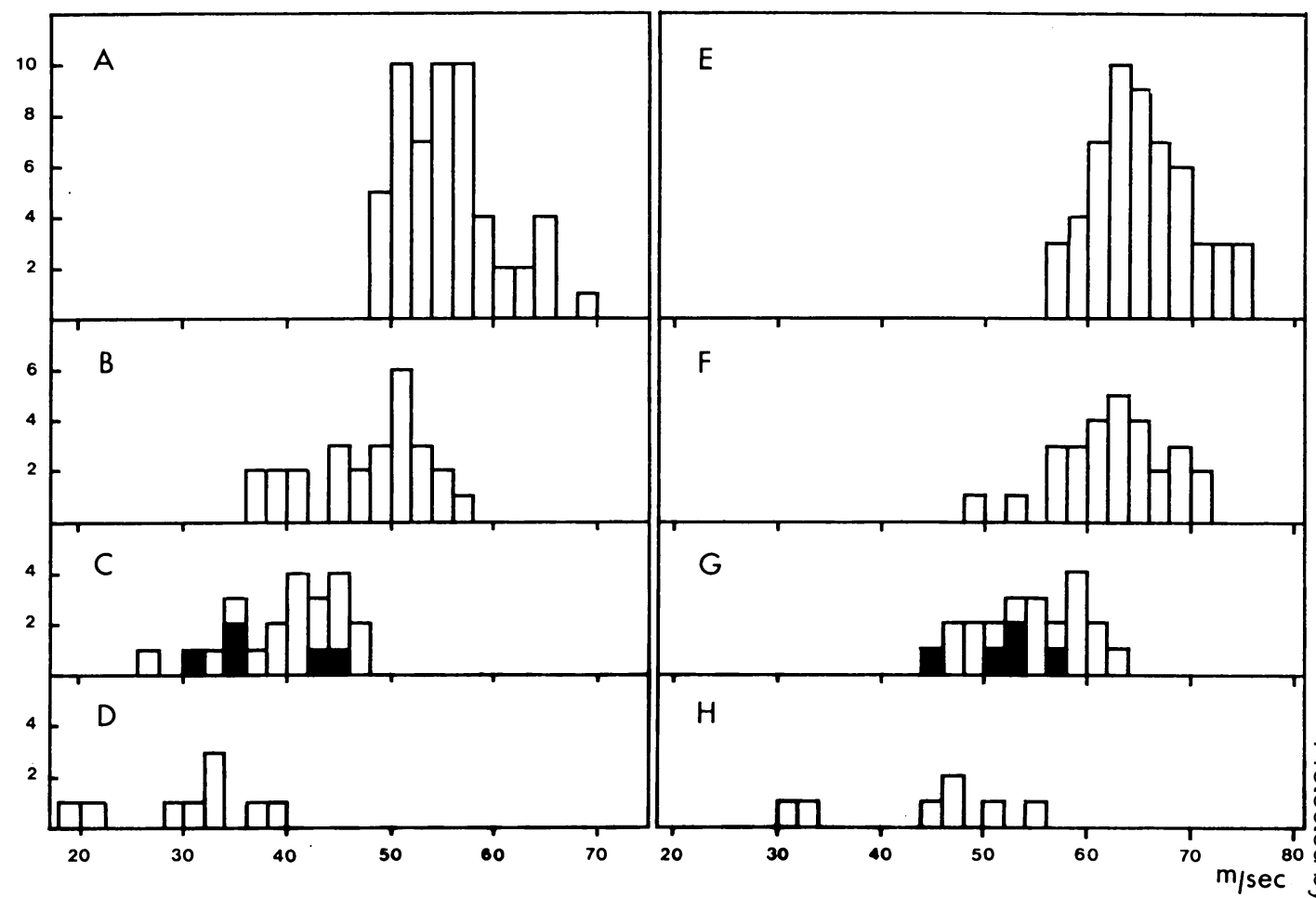

FIG. 1. Maximal sensory $C V$ in the distal (A, B, C, D) and proximal (E, F, G, H) segment of the median 8 nerve. A, E: 55 normal subjects. B, F: 26 diabetic patients without clinical neuropathy. $\mathrm{C}, \mathrm{G}: \mathbf{\square}:$ five $\frac{0}{0} \underset{\mathbb{D}}{\mathbb{D}}$ diabetic patients with mononeuropathy in the femoral, peroneal, or ulnar nerve. $1: 17$ diabetic patients with sensory polyneuropathy restricted to the lower limbs. $\mathrm{D}, \mathrm{H}:$ nine diabetic patients with polyneuropathy in $\rightleftharpoons$ both upper and lower limbs. In two patients, the CV could not be evaluated proximally to the wrist.

segment (Fig. 1, D, H). These results were in striking contrast with the values found in normal subjects in which the maximal sensory nerve $\mathrm{CV}$ ranged from 48 to $69 \mathrm{~m} / \mathrm{sec}$ (mean $54 \mathrm{~m} / \mathrm{sec}$ ) in the distal and from 55 to $76 \mathrm{~m} / \mathrm{sec}$ (mean 64 $\mathrm{m} / \mathrm{sec}$ ) in the proximal segment of the median nerve (Fig. 1, A, E). A reduction of the maximal sensory nerve $\mathrm{CV}$ in the median nerve was also found but to a lesser degree, in patients for whom the clinical evidence of sensory neuropathy was confined to the lower limbs. In these 17 patients, the maximal sensory nerve $\mathrm{CV}$ fell beneath the normal value in the fingers-to-wrist segment: it ranged from 26 to $47 \mathrm{~m} / \mathrm{sec}$ (mean 39 $\mathrm{m} / \mathrm{sec}$ ). Proximally, the maximal sensory nerve $\mathrm{CV}$ was found within the normal range in 8 of these 17 patients. It ranged from 46 to $64 \mathrm{~m} / \mathrm{sec}$ (mean $52.1 \mathrm{~m} / \mathrm{sec}$ ) (Fig. 1, G).

The patients with mononeuropathy exhibited decreased maximal sensory nerve $\mathrm{CV}$ in both the distal and proximal segments of the seemingly $\stackrel{\mathscr{D}}{\mathbb{Q}}$ normal median nerve, except for one patient in $\underset{7}{\rightarrow}$ whom it fell within the normal range in the proximal segment (Fig. 1, C, G: black squares).

More unexpected were the findings in the 26 . diabetic patients without clinical evidence of neuropathy in the four limbs, since the maximato sensory nerve $\mathrm{CV}$ was between 36 to $58 \mathrm{~m} / \mathrm{sec}$ in 윽 the distal segment of the median nerve (mean $46^{\circ}$ $\mathrm{m} / \mathrm{sec}$ ) (Fig. 1, B). In 11 of the patients it was beneath the lowest value found in the normalo subjects. However, in the proximal segment, only two patients exhibited decreased maximalo sensory nerve CV: 48 and $53 \mathrm{~m} / \mathrm{sec}$. For theñ whole group, the maximal sensory nerve $\mathrm{CV}^{\circ}$ ranged from 48 to $72 \mathrm{~m} / \mathrm{sec}$ with a mean value of $61 \mathrm{~m} / \mathrm{sec}$ (Fig. 1, F). 
TABLE

SENSORY NERVE CONDUCTION VELOCITY IN FOUR GROUPS OF PATIENTS

\begin{tabular}{|c|c|c|c|c|c|c|}
\hline \multirow{2}{*}{$\begin{array}{l}\text { Maximal sensory } \\
\text { nerve CV } \\
(\mathrm{m} / \mathrm{sec})\end{array}$} & & \multirow{2}{*}{$\begin{array}{l}\text { Normal } \\
\text { subjects }\end{array}$} & \multicolumn{4}{|c|}{ Diabetic patients } \\
\hline & & & Group I & Group II & Group III & Group IV \\
\hline $\begin{array}{l}\text { Distal segment } \\
\quad \text { (fingers to wrist) }\end{array}$ & $\begin{array}{l}\text { Range } \\
\text { Mean }\end{array}$ & $\begin{array}{c}48 \text { to } 69 \\
54\end{array}$ & $\begin{array}{l}48 \text { to } 57 \\
52\end{array}$ & $\begin{array}{l}50 \text { to } 58 \\
52\end{array}$ & $\begin{array}{l}35 \text { to } 46 \\
42\end{array}$ & $\begin{array}{c}18 \text { to } 46 \\
37\end{array}$ \\
\hline $\begin{array}{l}\text { Proximal segment } \\
\text { (wrist to elbow) }\end{array}$ & $\begin{array}{l}\text { Range } \\
\text { Mean }\end{array}$ & $\begin{array}{c}55 \text { to } 76 \\
64\end{array}$ & $\begin{array}{l}55 \text { to } 72 \\
64\end{array}$ & $\begin{array}{c}55 \text { to } 64 \\
60\end{array}$ & $\begin{array}{l}56 \text { to } 68 \\
60\end{array}$ & $\begin{array}{l}31 \text { to } 55 \\
46\end{array}$ \\
\hline $\begin{array}{l}\text { Proximal segment } \\
\text { (elbow to axilla) }\end{array}$ & $\begin{array}{l}\text { Range } \\
\text { Mean }\end{array}$ & 64 & 64 & 64 & $\begin{array}{l}61 \text { to } 70 \\
65\end{array}$ & $\begin{array}{l}31 \text { to } 71 \\
\quad 49\end{array}$ \\
\hline
\end{tabular}

NERVE ACTION POTENTIAL (NAP): AMPLITUDE AND SYNCHRONIZATION Studies of the shape and amplitude of the nerve action potential (NAP) recorded at various sites along the nerve course are essential in the evaluation of a neuropathy. In normal subjects the amplitude of the triphasic nerve response was 15 to $45 \mu \mathrm{V}$ at the wrist.

Fifty-three patients were separated in four groups of increasingly severe nerve involvement (Table).
GROUP I: NORMAL RESPONSE IN UPPER LIMB A 35 year old male had been diabetic and treated with insulin for two years. Clinical examination disclosed no sign of neuropathy. The NAP evoked at the wrist by stimulation of digits II and III was triphasic, without a late component. Its amplitude was $32 \mu \mathrm{V}$ (Fig. 2, B). More proximally, its shape was not altered but for a slightly augmented duration due to the normal desynchronization of the afferent volley. The

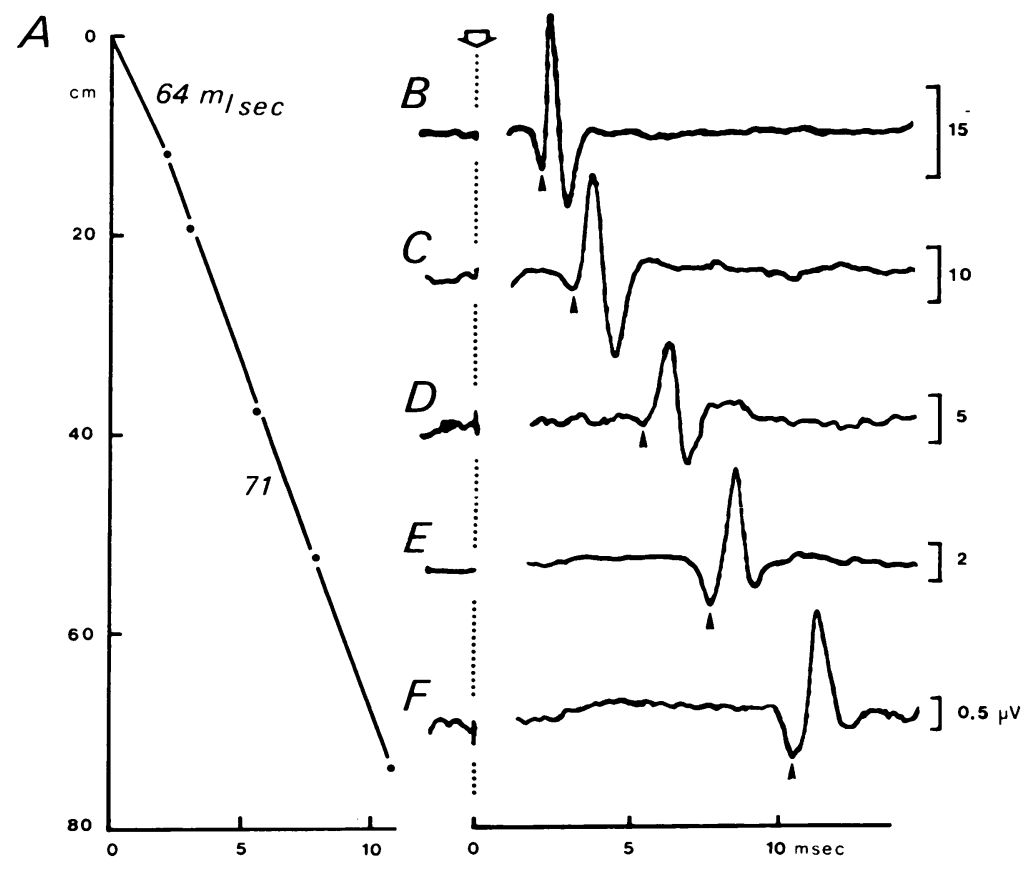

FIG. 2. Male patient, 35 years. Insulin-dependent diabetes. Negative neurological examination. Average median nerve responses evoked by electrical stimulation of digits II and III, recorded at the wrist (B), in the mid forearm (B), at the elbow (D), axilla (E), and supraclavicular notch (F). The initial negative deflection (arrow) is taken as the latency. Sensory nerve maximal CV evaluated by comparing the latency of the response with the distance of the recording electrode from the stimulation site $(\mathrm{A})$. 


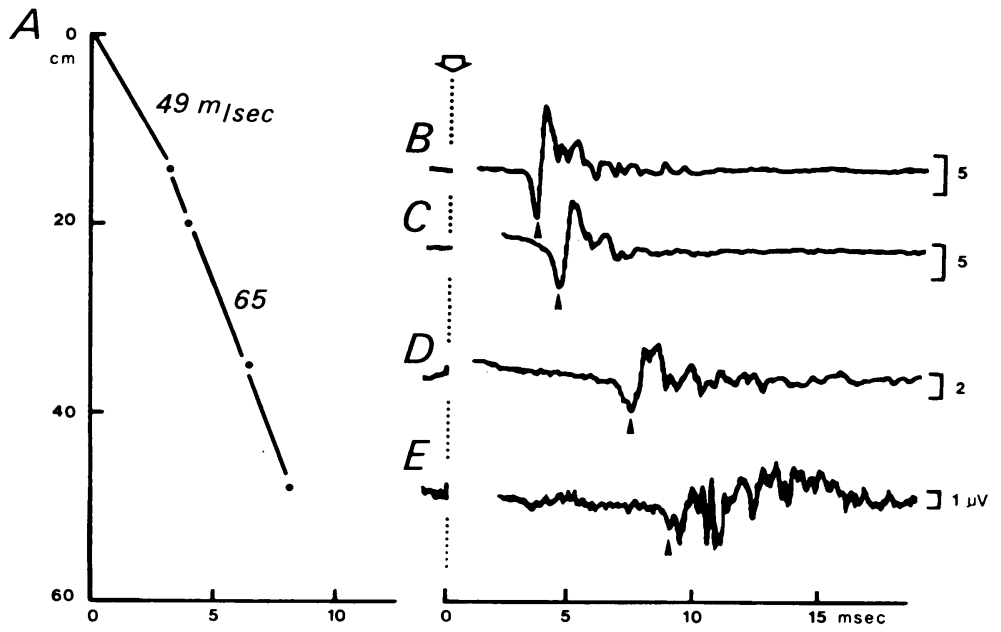

FIG. 3. Male patient, 45 years. Insulin-dependent diabetes. Negative neurological examination. Median nerve responses recorded at the wrist $(\mathrm{B})$, in the forearm $(\mathrm{C})$, at the elbow (D), and axilla (E). Maximal sensory nerve $\mathrm{CV}$ evaluated in the diagram (A).

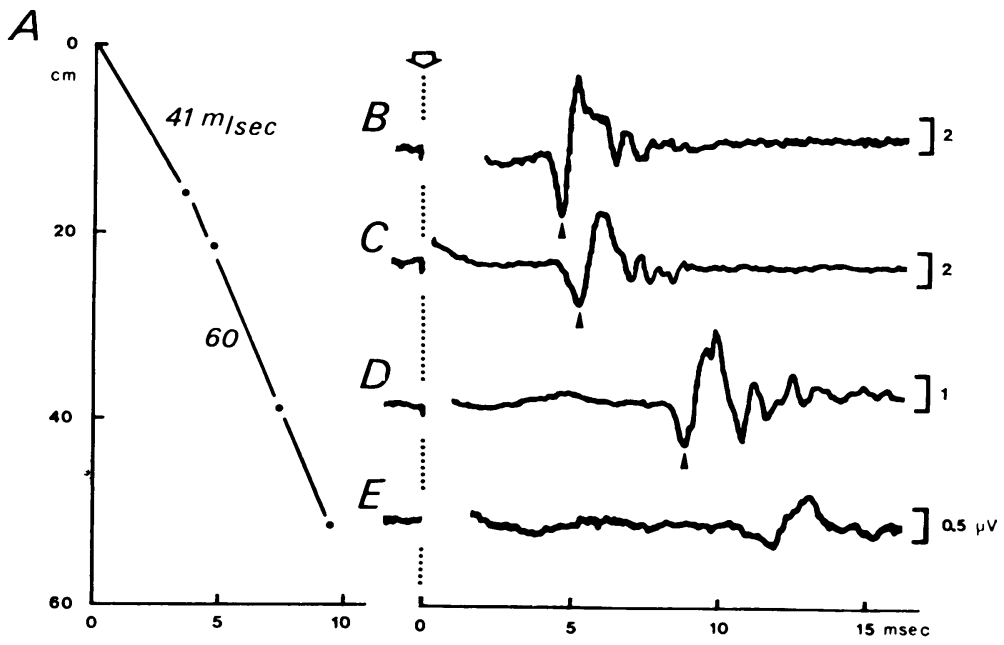

FIG. 4. Female patient, 40 years. Insulin-dependent diabetes. Clinical signs of neuropathy confined to the lower limbs. Median nerve responses recorded at the wrist $(\mathrm{B})$, in the forearm $(\mathrm{C}), ?$ at the elbow (D), and axilla (E). Maximal sensory nerve $C V$ evaluated in the diagram (A).

amplitude of the NAP was $12 \mu \mathrm{V}$ at the elbow (Fig. 2, D), 6.5 $\mu \mathrm{V}$ at the axilla (Fig. 2, E), and $2 \mu \mathrm{V}$ at the supraclavicular notch (Fig. 2, F). The maximal sensory nerve $\mathrm{CV}$ was $64 \mathrm{~m} / \mathrm{sec}$ in the hand and $71 \mathrm{~m} / \mathrm{sec}$ in the wrist-to-supraclavicular notch (Fig. 2, A).

Similar results were found in eight other patients, none of whom presented symptoms or signs of neuropathy in any limb.

GROUP II: NORMAL MAXIMAL SENSORY NERVE CV WITH DESYNCHRONIZATION OF THE RESPONSE A
45 year old diabetic male showed no clinical evidence of neuropathy. The duration of the disease was thought to be three years. The maxi-3. mal sensory nerve CV was normal in the fingersto-wrist segment $(49 \mathrm{~m} / \mathrm{sec})$ and the wrist-to- 3 axilla segment $(65 \mathrm{~m} / \mathrm{sec})$ (Fig. 3, A). The ampli-o tude of the NAP at the wrist was $15 \mu \mathrm{V}$, still within the normal range, but late components? were conspicuous and the minimal sensory nerven $\mathrm{CV}$ may be evaluated at $13 \mathrm{~m} / \mathrm{sec}$ (Fig. 3, B). Proximally, the NAP desynchronization increased so that the amplitude of the late com-w 

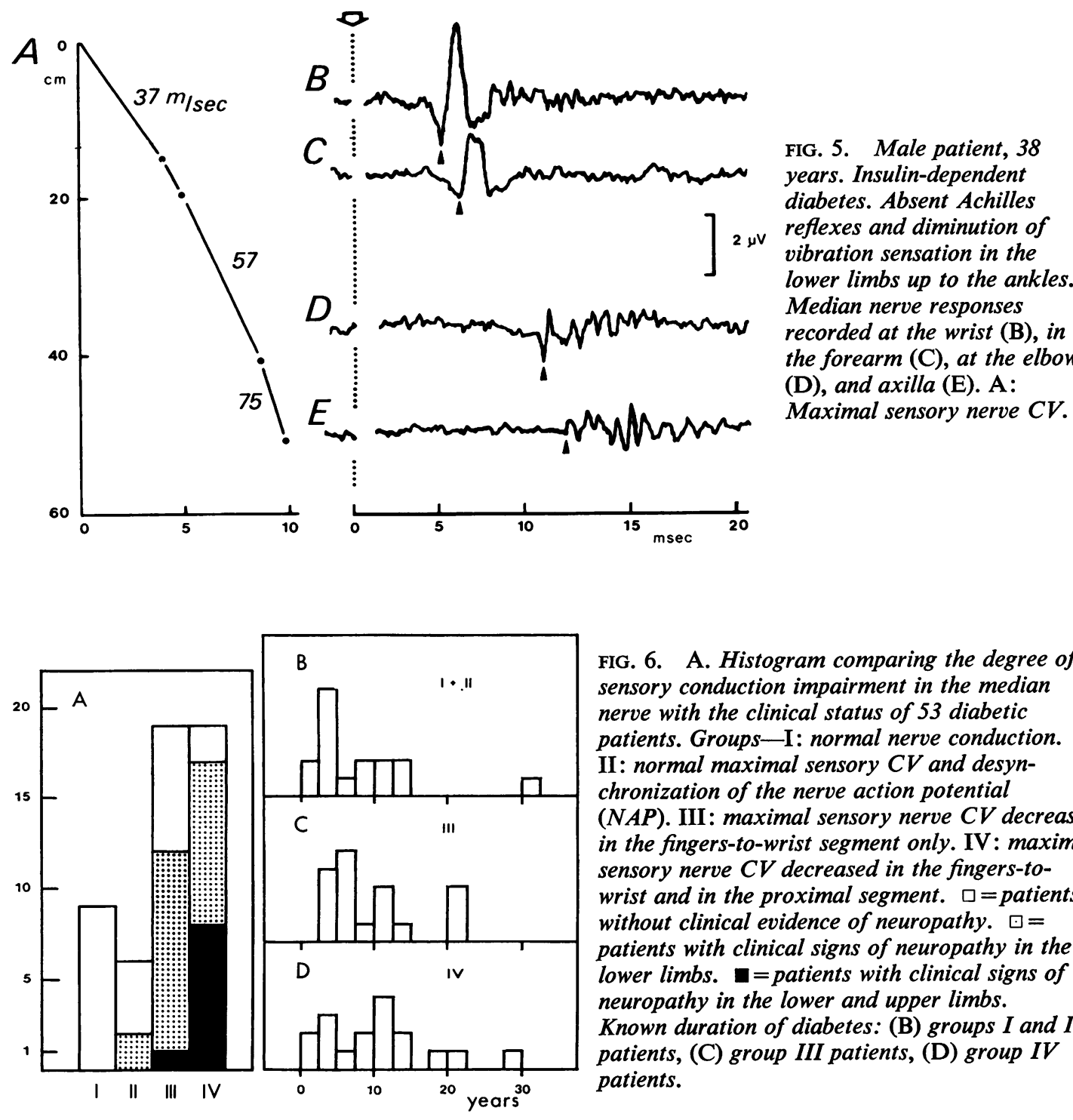

FIG. 6. A. Histogram comparing the degree of sensory conduction impairment in the median nerve with the clinical status of 53 diabetic patients. Groups-I: normal nerve conduction. II: normal maximal sensory $C V$ and desynchronization of the nerve action potential (NAP). III: maximal sensory nerve $C V$ decreased in the fingers-to-wrist segment only. IV: maximal sensory nerve $C V$ decreased in the fingers-towrist and in the proximal segment. $\square=$ patients without clinical evidence of neuropathy. $\square=$ patients with clinical signs of neuropathy in the lower limbs. $\mathbf{\square}=$ patients with clinical signs of neuropathy in the lower and upper limbs. Known duration of diabetes: (B) groups I and II patients, (C) group III patients, (D) group IV patients.

ponents were not different from the amplitude of the initial peak. At the elbow, the amplitude of the initial peak was $6 \mu V$ (Fig. 2, D). Such findings were characteristic of six patients.

GROUP III: REDUCED MAXIMAL SENSORY NERVE CV IN DISTAL SEGMENT ONLY This group included 19 patients (Fig. 4). A 40 year old woman with diabetes of three years' duration had slight but unequivocal signs of neuropathy confined to the lower limbs. The maximal sensory nerve $\mathrm{CV}$ was decreased to $41 \mathrm{~m} / \mathrm{sec}$ in the finger-wrist segment of the median nerve but within the normal range proximal to the wrist, $60 \mathrm{~m} / \mathrm{sec}$ (Fig. 4, A). The NAP was polyphasic at the wrist and the minimal sensory nerve $\mathrm{CV}$ was $16 \mathrm{~m} / \mathrm{sec}$. Its amplitude was reduced: $8 \mu \mathrm{V}$ (Fig. 3, B). In the forearm (Fig. 3, C), and at the elbow (Fig. 3, D) the response was respectively 6 and $3 \mu \mathrm{V}$. At the axilla late components were hardly recognizable, 
probably because of inadequate location of the electrode.

GROUP IV: REDUCED MAXIMAL SENSORY NERVE CV IN BOTH DISTAL AND PROXIMAL SEGMENTS In 19 patients, the maximal sensory nerve $C V$ was also decreased proximal to the wrist (Fig. 5). In a 38 year old diabetic patient with a moderate to severe neuropathy in the lower limbs, the maximal sensory nerve $\mathrm{CV}$ was $37 \mathrm{~m} / \mathrm{sec}$ in the hand, $57 \mathrm{~m} / \mathrm{sec}$ between the wrist and the elbow and $72 \mathrm{~m} / \mathrm{sec}$ in the upper arm (Fig. 5, A). At the wrist, the minimal sensory nerve $\mathrm{CV}$ was 13 $\mathrm{m} / \mathrm{sec}$, the response was polyphasic and its initial peak was $4 \mu \mathrm{V}$. The reduction of the maximal sensory nerve $\mathrm{CV}$ was always more marked distally. In the upper arm, the CV tended to reach a normal value.

CORRELATION WITH CLINICAL DATA (Fig. 6) In the nine patients of group I, no evidence of neuropathy was found on careful clinical@ examination.

Two of the six patients of group II presented signs of mild sensory neuropathy confined to the lower limbs. In group III, clinical neuropathy inco the lower limbs was a common occurrence. It was found in 12 of 19 patients. Moreover, the upper limbs were involved in one additional patient in. this group. In group IV, clinical evidence of neuropathy was the rule. It was present in $17 \frac{\text { ? }}{0}$ patients, affecting the upper limbs in eight of $\frac{\mathrm{T}}{\mathrm{O}}$ them. The mean duration of the diabetes was $\frac{\overline{\bar{s}}}{\overline{2}}$ seven years for group I and II (Fig. 6, B), nine $\frac{\mathbb{Q}}{2}$ years for group III (Fig. 6, C), and nine years forg group IV (Fig. 6, D). The distribution of the patients in each group is roughly similar in cases of diabetes of less than 15 years' duration (Fig. $\vec{\omega}$ 6, B-D).

In each group, the ages of the patients were in the same range: 25 to 68 years for group I, 29 to $\omega$ 65 years for group II, 18 to 67 years for group III,

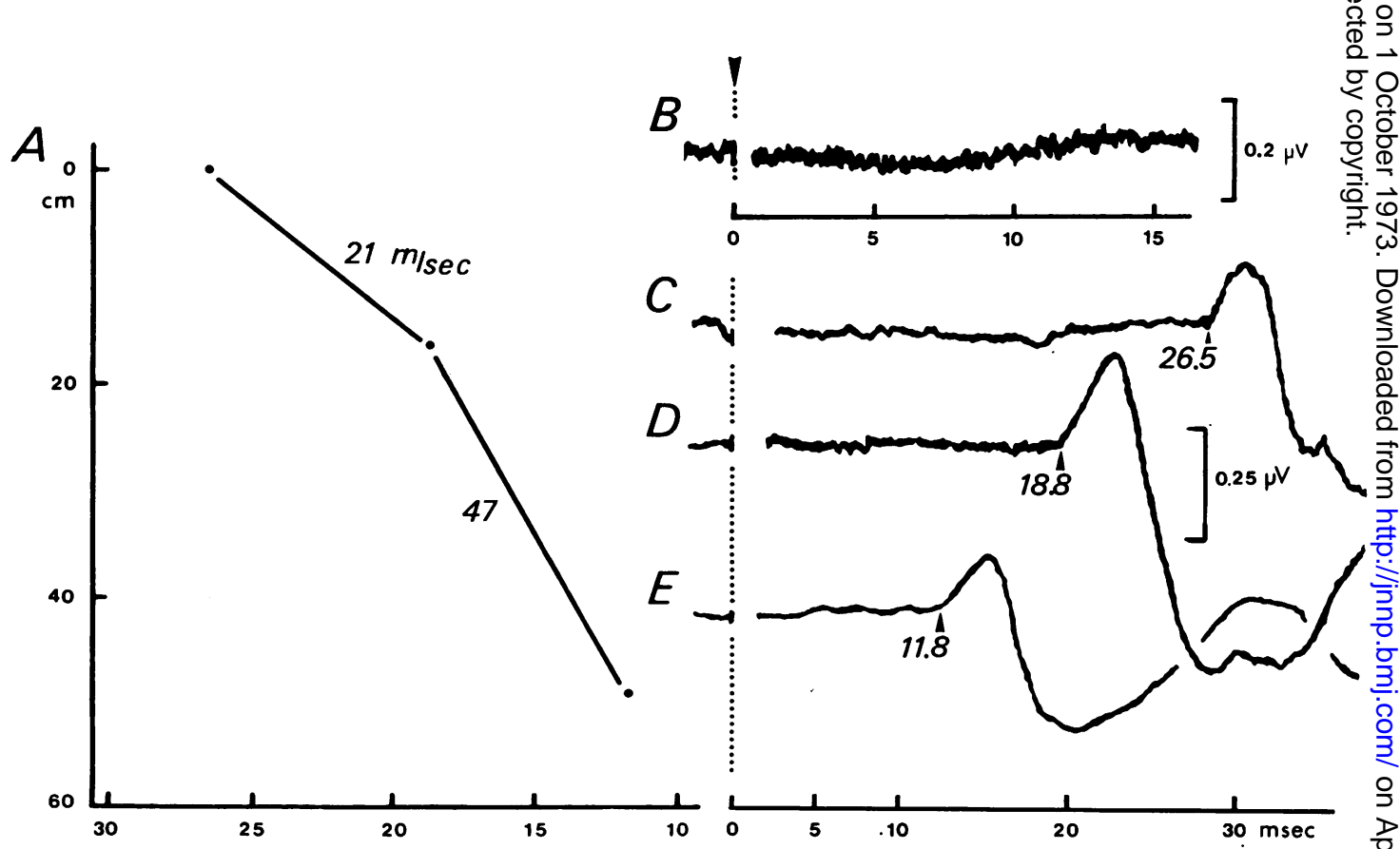

FIG. 7. Male patient, 50 years. Insulin-dependent diabetes. Pseudo-tabetic syndrome in all limbs. Absence of median nerve response at the wrist by supramaximal stimulation of digits II and III (B). Evaluation of maximalo sensory nerve $C V$ from the latency of the cerebral evoked potentials (A). C, D, E: average cerebral responsesn from the contralateral parietal hand focus and evoked by electrical stimulation of digits II and III (C) or medianN nerve at the level of the wrist (D) or axilla (E). 
and 26 to 64 years for group IV. The mean age showed a gradual increase from group I to group IV; it was respectively $46,48,50$, and 52 years.

CEREBRAL EVOKED POTENTIALS (CEP) The latency of the average cerebral potential evoked by stimulation of the fingers and recorded at the controlateral focus of the hand (CEP) is fairly constant and shows little variations in successive runs on the same subject. It varies between $17 \cdot 5$ and $20.5 \mathrm{msec}$ in normal subject and may be evaluated to about $0.5 \mathrm{msec}$ (Desmedt, 1971; Desmedt et al., 1973).

In 28 diabetic patients the latency of the CEP ranged from 18 to $29.5 \mathrm{msec}$. When delayed, the latency seemed related to the decrease in maximal sensory nerve $\mathrm{CV}$, the cortical delay being very similar to the delay of the peripheral response recorded at the most proximal site.

In two patients, no sensory NAP could be recorded even at the wrist. One of them, a 50 year old man, had poorly controlled diabetes of 10 years' duration. Deep reflexes were abolished. He presented a pseudo-tabetic syndrome in the lower limbs: touch and proprioceptive sensation were severely impaired, deep reflexes were absent. Painless ulcers were present on the soles. In the upper limbs, the position sensation was impaired and deep reflexes were weak. The early components of the cortical potential evoked by stimulation of the fingers were small: $0.55 \mu \mathrm{V}$ (normal: 2 to $5 \mu \mathrm{V}$ ). The latency of the first negative component $\left(\mathrm{N}_{1}\right)$ was $26.5 \mathrm{msec}$ (Fig. 7). By stimulation of the median nerve trunk at the wrist and axilla, the cortical responses recorded at the controlateral hand focus exhibited a latency of respectively $18.8 \mathrm{msec}$ and $11.8 \mathrm{msec}$. The shapes of the three responses were very similar, so that the afferent volleys elicited at the different levels of stimulation in the upper limb can be considered to be fairly comparable. The latencies of these responses can thus be compared to evaluate the peripheral $\mathrm{CV}$ of the afferent volley. By this technique, the $\mathrm{CV}$ was evaluated at $21 \mathrm{~m} / \mathrm{sec}$ from fingers to wrist and at $47 \mathrm{~m} / \mathrm{sec}$ from elbow to axilla. It must be emphasized that the latency of the central response evoked by stimulation at the axilla is abnormally long: $11.8 \mathrm{msec}$ against a normal value ranging from 9.5 to $11 \mathrm{msec}$ (Desmedt and
Noël, 1973). This points to an impaired propagation of the afferent volley proximal to the axilla.

In the other patient of this group, a 55 year old diabetic whose upper limbs were amyotrophic and paretic, the latency of the cerebral response was $28.8 \mathrm{msec}$ when evoked by stimulation of the fingers and $13.4 \mathrm{msec}$ by stimulation at the axilla. The mean sensory nerve $\mathrm{CV}$ was estimated at $36.5 \mathrm{~m} / \mathrm{sec}$ in the segment fingers-to-axilla.

\section{DISCUSSION}

The recording of a nerve action potential of normal latency, amplitude, and wave form requires synchronous conduction in the large myelinated fibres (Dawson, 1956; Gilliatt and Sears, 1958; Debecker and Desmedt, 1964; Buchthal and Rosenfalck, 1966). In diabetic neuropathy, the sensory nerve potentials are characterized by a reduced amplitude, a polyphasic shape and an increased latency of the initial peak. These alterations can also appear, though to a lesser degree, when a careful clinical examination of the nervous system is negative (Downie and Newell, 1961; Gilliatt and Willison, 1962; Chopra et al., 1969; Lamontagne and Buchthal, 1970; Noël et al., 1971).

Such subclinical sensory neuropathy may be an early accompaniment of diabetes as substantiated by the finding of abnormal nerve potentials in patients with diabetes of recent onset (Noël et al., 1971, Fig. 3). These alterations are probably related to segmental demyelination, which is the main, though by no means unique, pathological finding in diabetic neuropathy (Dolman, 1963; Thomas and Lascelles, 1966). Of particular significance are the findings of Chopra et al. (1969) who described myelin breakdown in sural nerves of diabetic patients without clinical signs of neuropathy, thus affording an anatomical background to subclinical neuropathy.

The anatomical studies were performed on biopsy materials from distal nerves so that available data on more proximal nerves remain scarce (Olsson, Säve-Sôderbergh, Sourander, and Angervall, 1968).

Averaging with fast computers now permits demonstration of very small responses (Gilliatt et al., 1961; Liberson et al., 1965; Buchthal and Rosenfalck, 1971) down to $0.05 \mu \mathrm{V}$ in this laboratory (Desmedt, 1971; Desmedt and Noël, 
1973) so that the maximal sensory nerve conduction velocity can be measured along the arm up to the brachial plexus, even in pathological cases. Furthermore, the shape of the response gives additional clue to the presence of slower conducting fibres and a minimal sensory nerve conduction velocity can be estimated (Buchthal, 1973). The present data on 59 patients, at various stages of the disease, illustrate in a way the natural history of diabetic sensory neuropathy.

A normal maximal sensory nerve $\mathrm{CV}$ and triphasic response at the wrist suggest the integrity of the investigated nerve. In the patients presenting such characteristics (group I), no clinical evidence of neuropathy was found in the upper or lower limbs.

In normal subjects, slow components are occasionally disclosed at the wrist with optimally located recording electrodes. Their amplitude is inferior to $0.5 \mu \mathrm{V}$ and the minimal $\mathrm{CV}$ remains above $20 \mathrm{~m} / \mathrm{sec}$ (Buchthal and Rosenfalck, 1971. In our group II patients, the nerve response was desynchronized at the wrist with late components of 1.2 to $5 \mu \mathrm{V}$ and a minimal $\mathrm{CV}$ between 10 and $20 \mathrm{~m} / \mathrm{sec}$. These findings indicate hampered conduction in the distal segment of the nerve. A number of sensory fibres remain functionally intact as indicated by the normal latency of the initial peak. However, the temporal dispersion of the fibre action potentials accounts for a slightly reduced amplitude of the potential to $50-60 \%$ (Gilliatt, 1961; Buchthal and Rosenfalck, 1971). These mild abnormalities remain frequently subclinical and represent the earliest stage of diabetic neuropathy. Nevertheless, clinical signs restricted to the lower limbs are occasionally found (Fig. 6), evidencing a widespread involvement of the peripheral nerve at an early stage of the disease.

Eventually, more and more large fibres are affected until most afferent fibres are involved. The maximal sensory nerve $\mathrm{CV}$ is then decreased in the distal portion of the limb and the desynchronization of the response is enhanced (group III).

In group IV, the maximal sensory nerve $\mathrm{CV}$ is reduced in the forearm and arm. It is not equally low along the whole course of the nerve. The CV is very low in the fingers-to-wrist segment, gradually increases, and reaches a normal value in the arm or at the axilla (Fig. 5). Such findings are frequently associated with a clinical neuro-市 pathy in the four limbs. Indeed, proximally de-O creased $\mathrm{CV}$ is present in 10 of the 19 patients with signs referring to the lower limbs and not unexpectedly in each patient for whom clinical examination discloses signs of neuropathy in both lower and upper limbs.

Thus the reduction of sensory nerve CV seems. to start at the periphery and eventually to pro- $\overrightarrow{\vec{F}}$ gress towards the root of the limb. This processo cannot be ascribed solely to ageing, since it is much more marked in diabetic patients than in $\frac{\bar{T}}{\vec{D}}$ the normal elderly (Buchthal and Rosenfalck, $\stackrel{\mathbb{Q}}{\varrho}$ 1966; Noël et al., 1971, Fig. 1). Moreover, it seems to be rather independent of the known $\vec{\circ}$ duration of the diabetes, which is at variance with the well-known fact that severe neuropathy is mostly encountered in patients with poorly controlled and longstanding diabetes (Pirart, 1965).

The proximal extension of neuropathic in-ir volvement is clearly related to the appearance ared increasing severity of clinical signs of neurs pathy, first in the lower and then upper limbs. This proximo-distal gradient is similar to that observed in motor nerves (Lawrence and Locke, $\frac{\Upsilon}{0}$ 1961; Lamontagne and Buchthal, 1970). 응 윰

From these data, it may be proposed that sed mental demyelination should be most marked the distal part of the peripheral nerves, which is ${ }^{\omega}$ in keeping with the anatomical findings of Olsson et al. (1968).

In patients presenting a severe neuropathy, the amplitude of the nerve potential is reduced to $\frac{\mathbb{\Phi}}{\circ}$ such a degree that a loss of active fibres must be $\stackrel{\varrho}{\Rightarrow}$ postulated. This could be the result either of a conduction block in fibres demyelinated for $\mathrm{a}$ long distance or of the degeneration of a number of axons (McDonald, 1963; 1973; Dyck and Lambert, 1966; Dyck, 1973). Both mechanisms appear to be at work. While in diabetic neuro-: pathy of recent onset, segmental demyelination 3 . may be the only abnormal finding (Thomas and 8 Lascelles, 1966), combined axonal and myelin changes suggesting Wallerian degeneration are 웅 found in chronic or severe cases (Chopra et al., $>$ 1969). Both histological and electrophysiological evidence point to an initially demyelinating pro- N cess with subsequent loss of nerve fibres.

Of particular significance are the two patients suffering from a severe neuropathy affecting all ${ }_{0}^{\omega}$ 
limbs in whom no sensory response was recorded even at the wrist. A large reduction of the number of active fibres can be postulated if the recording electrodes were accurately located. This is assessed by the presence of the cerebral potentials evoked by stimulation of the fingers and of the median nerve through the same electrodes as used for the fruitless recording of the nerve potential. The latencies of these potentials were significantly increased, indicating a very slow conduction more marked in the distal segment of the limb (Fig. 5). Moreover, stimulation of the nerve at the axilla elicited a cerebral response with abnormally long latency in both cases, which suggests that diabetic neuropathy eventually involved the nerve proximal to the axilla.

There are other examples of the usefulness of the cerebral evoked potentials for providing evidence on pathological afferent conduction in nerves with severe lesions (Desmedt, 1971; Desmedt and Noël, 1973).

While sensory polyneuropathy is widely held to be the result of metabolic impairment of the Schwann cell (cf Bruyn and Garland, 1970; Eliasson, 1971), it was proposed that diabetic mononeuropathy (multiplex) was due to a specific angiopathy affecting the vasa nervorum (Fagerberg, 1959). The five patients who presented a clinical mononeuropathy, affecting either the lower or upper limbs, exhibited abnormal sensory nerve action potential in the median nerve. Mild clinical signs of sensory neuropathy restricted to the lower limbs were present in three of them. These data point to a widespread involvement of the peripheral nerves which may be assumed to predispose them to further local injuries, thus leading to the clinical impairment. That such local injuries may be of ischaemic origin is evidenced by the observations of Raff et al. (1968) who described infarctions in the involved nerves of diabetic patients with mononeuropathy. On the other hand, minor traumas may well be precipitating factors in revealing a latent neuropathic involvement, as substantiated by the frequent observation that the affected nerves in diabetic mononeuropathy are those commonly involved by mechanical neuropathies (Mulder et al., 1961; Gilliatt and Willison, 1962). We think that the diabetic nature of a so-called mono-neuropathy occurring in a diabetic patient can generally be substantiated by the finding of subclinical involvement of other nerves in nerve conduction tests.

The author wishes to thank Professor J. E. Desmedt for advice in the preparation of this paper and Dr. J. P. Lauvaux who referred the patients for investigation.

\section{REFERENCES}

Ball, G. J., Saunders, M. G., and Schnabl, J. (1971). Determination of peripheral sensory nerve conduction velocities in man from stimulus response delays of the cortical evoked potentials. Electroencephalography and Clinical Neurophysiology, 30, 409-414.

Bischoff, B. (1963). Die diabetische Neuropathie, Thieme: Stuttgart.

Buchthal, F. (1973). Sensory and motor conduction in polyneuropathies. In New Developments in Electromyography and Clinical Neurophysiology. Vol. 2, pp. 259-271. Edited by J. E. Desmedt: Karger, Basel.

Buchthal, F., and Rosenfalck, A. (1966). Evoked action potentials and conduction velocity in human sensory nerves. Brain Research, 3, 1-122.

Buchthal, F., and Rosenfalck, A. (1971). Sensory potentials in polyneuropathy. Brain, 94, 241-262.

Bruyn, G. N., and Garland, H. (1970). Neuropathies of endocrine origin. In Handbook of Clinical Neurology, vol. 8, pp. 29-71. Edited by P. J. Vinken and G. W. Bruyn. North Holland: Amsterdam.

Chochinov, R. H., Ullyot, L. E., and Moorhouse, J. A. (1972). Sensory perception thresholds in patients with juvenile diabetes and their close relatives. New England Journal of Medicine, 286, 1233-1237.

Chopra, J. S., Hurwitz, L. J., and Montgomery, D. A. D. (1969). The pathogenesis of sural nerve changes in diabetes mellitus. Brain, 92, 391-418.

Dawson, G. D. (1956). The relative excitability and conduction velocity of sensory and motor nerve fibres in man. Journal of Physiology, 131, 436-451.

Debecker, J., and Desmedt, J. E. (1964). Les potentiels évoqués cérébraux et les potentiels de nerf sensible chez l'homme. L'utilisation de l'ordinateur numérique Mnemotron. 400-B. Acta Neurologica et Psychiatrica Belgica, 64, 1212-1248.

Desmedt, J. E. (1971). Somatosensory cerebral evoked potentials in man. In Handbook of Electroencephalography and Clinical Neurophysiology. Vol. 9, pp. 55-82. Edited by A. Rémond. Elsevier: Amsterdam.

Desmedt, J. E., Franken, L., Borenstein, S., Debecker, J., Lambert, C., and Manil, J. (1966). Le diagnostic des ralentissements de la conduction afférente dans les affections des nerfs périphériques: intérêt de l'extraction du potentiel évoqué cérébral. Revue Neurologique, 115, 255262.

Desmedt, J. E., and Noël, P. (1973). Average cerebral evoked potentials in the evaluation of lesions of the sensory nerves and the central somatosensory pathway. In New Developments in Electromyography and Clinical Neurophysiology. Vol. 2, pp. 352-371. Edited by J. E. Desmedt. Karger: Basel.

Desmedt, J. E., Noël, P., Debecker, J., and Namèche, J. (1973). Maturation of afferent conduction velocity as studied by sensory nerve potentials and by cerebral evoked potentials. In New Developments in Electromyography and Clinical Neurophysiology. Vol. 2, pp. 52-63. Edited by J. E. Desmedt. Karger: Basel. 
Dolman, C. L. (1963). The morbid anatomy of diabetic neuropathy. Neurology (Minneap.), 13, 135-142.

Downie, A. W., and Newell, D. J. (1961). Sensory nerve conduction in patients with diabetes mellitus and controls. Neurology (Minneap.), 11, 876-882.

Dyck, P. J. (1973). Ultrastructural alterations in myelinated fibers. In New Developments in Electromyography and Clinical Neurophysiology. Vol. 2, pp, 192-226. Edited by J. E. Desmedt. Karger: Basel.

Dyck, P. J., and Lambert, E. H. (1966). Numbers and diameters of nerve fibers and compound action potential of sural nerve: controls and hereditary neuromuscular disorders. Transactions of the American Neurological Association, 91, 214-217.

Eliasson, S. G. (1971). Disorders of the nervous system in diabetes. Medical Clinics of North America, 55, 1001-1006.

Fagerberg, S.-E. (1959). Diabetic neuropathy. Acta Medica Scandinavica, 164, Suppl. 345.

Giblin, D. R. (1964). Somatosensory evoked potentials in healthy subjects and in patients with lesions of the nervous system. Annals of the New York Academy of Science, 112 93-142.

Gilliatt, R. W. (1961). Sensory nerve conduction in man. Proceedings of the Royal Society of Medicine, 54, 324-326.

Gilliatt, R. W., Melville, I. D., Velate, A. S., and Willison, R. G. (1965). A study of normal nerve action potentials using an averaging technique (barrier grid storage tube). Journal of Neurology, Neurosurgery, and Psychiatry, 28, 191-200.

Gilliatt, R. W., and Sears, T. A. (1958). Sensory nerve action potentials in patients with peripheral nerve lesions. Journal of Neurology, Neurosurgery, and Psychiatry, 21, 109-118.

Gilliatt, R. W., and Willison, R. G. (1962). Peripheral nerve conduction in diabetic neuropathy. Journal of Neurology, Neurosurgery, and Psychiatry, 25, 11-18.

Gregersen, G. (1967). Diabetic neuropathy: influence of age, sex, metabolic control, and duration of diabetes on motor conduction velocity. Neurology (Minneap.), 17, 972-980.

Halliday, A. M., and Wakefield, G. S. (1963). Cerebral evoked potentials in patients with dissociated sensory loss. Journal of Neurology, Neurosurgery, and Psychiatry, 26, 211-219.

Heinrichs, R. W., and Moorhouse, J. A. (1969). Touchperception thresholds in blind diabetic subjects in relation to the reading of Braille type. New England Journal ok Medicine, 280, 72-75.

Lamontagne, A., and Buchthal, F. (1970). Electrophysiological studies in diabetic neuropathy. Journal of Neurology Neurosurgery, and Psychiatry, 33, 442-452.

Lawrence, D. G., and Locke, S. (1961). Motor nerve conduc- 0 tion velocity in diabetes. Archives of Neurology, 5, 483-489)

Liberson, W. T., Gratzer, M., and Zalis, A. (1965). The use of CAT in recording median, ulnar, tibial, peroneal and, dorsal root potentials. Sixth International Congress of Electroencephalography and Clinical Neurophysiology; Vienna, 1965, pp. 685-688.

McDonald, W. I. (1963). The effects of experimental demyelination on conduction in peripheral nerve. 2. Electrophysiological observations. Brain, 86, 501-524.

McDonald, W. I. (1973). Experimental neuropathy. The use of diphtheria toxin. In New Developments in Electro- $\mathbb{\mathbb { D }}$ myography and Clinical Neurophysiology. Vol. 2, pp. 128_ 144. Edited by J. E. Desmedt. Karger: Basel.

Mulder, D. W., Lambert, E. H. Bastron, J. A and Sprag R. G. (1961). The neuropathies associated with diabetes. mellitus. A clinical and electromyographic study of 103 un- $\overrightarrow{-}$ selected diabetic patients. Neurology (Minneap.), 11, 275- $\vec{\omega}$ 284.

Noël, P., and Desmedt, J. E. (1972). Les potentiels évoqués cérébraux dans l'hémiplégie infantile. Revue d'Électro=0 encéphalographie et de Neurophysiologie Clinique, 2, 189- W. 194.

Noël, P., Lauvaux, J. P., and Pirart, J. (1971). Upper limbs. diabetic neuropathy: a clinical and electrophysiologicalo study. Hormone and Metabolic Research, 3, 386-392. त) क

Olsson, Y., Säve-Söderbergh, J., Sourander, P., å̊ $\mathrm{d}$ 음 Angervall, L. (1968). A patho-anatomical study of thecentral and peripheral nervous system in diabetes of eactyo onset and long duration. Pathologia Europaea, 3, 62-79.

Pirart, J. (1965). Diabetic neuropathy: a metabolic or윰응 vascular disease? Diabetes, 14, 1-9.

Raff, M. C., Sangalang, V., and Asbury, A. K. (1968). Ischemic mononeuropathy multiplex associated wis diabetes mellitus. Archives of Neurology, 18, 487-499.

Thomas, P. K., and Lascelles, R. G. (1966). The pathology of diabetic neuropathy. Quarterly Journal of Medicine, 35, 489-509. 